\title{
Crowdsourcing como uma nova espécie de relação de emprego?
}

\author{
Crowdsourcing as a new kind of employment relationship? \\ ¿Crowdsourcing como un nuevo tipo de relación de trabajo?
}

Recebido: 29/11/2021 | Revisado: 04/12/2021 | Aceito: 05/12/2021 | Publicado: 14/12/2021

\author{
Antônio Hiago Paiva de Oliveira \\ ORCID: https://orcid.org/0000-0003-3606-0024 \\ Universidade Federal do Rio Grande do Norte, Brasil \\ E-mail: hiagopaiva31@gmail.com \\ Carlos Francisco do Nascimento \\ ORCID: https://orcid.org/0000-0001-6574-4949 \\ Universidade Federal do Rio Grande do Norte, Brasil \\ E-mail: hiagopaiva31@gmail.com
}

\begin{abstract}
Resumo
Com a pandemia da Covid-19, o desemprego aumentou exponencialmente, apresentando como saída para muitos trabalhadores desempregados, o crowdsourcing, isto é, o trabalho uberizado. Este artigo tem como objetivo analisar de forma mais profunda o processo de uberização dos indivíduos, propondo uma discussão acerca da existência ou não dos requisitos básicos para a configuração do vínculo de emprego, tutelado pela legislação brasileira, que garante ao trabalhador abrangido por essa relação jurídica seus direitos trabalhistas. Para tanto, por meio de pesquisa jurisprudencial e bibliográfica, analisa o processo de uberização do trabalhador moderno, sobretudo em tempos de pandemia da Covid-19, para identificar aspectos/informações que ajudem a compreender se a uberização configura-se como emprego. Por fim, conclui-se que com o advento da pandemia da Covid-19 ampliou-se o número de trabalhadores informais que se tornaram uberizados; o Judiciário brasileiro ainda não firmou posicionamento pacífico acerca do reconhecimento do vínculo empregatício; torna-se necessária uma regulamentação legislativa própria, visando legalizar a situação desses trabalhadores.
\end{abstract}

Palavras-chave: Covid-19; Crowdsourcing; Relações Trabalhistas.

\begin{abstract}
With the Covid-19 pandemic, unemployment increased exponentially, presenting crowdsourcing, that is, uberized work, as a way out for many unemployed workers. This paper aims to analyze in greater depth the process of uberization of individuals, proposing a discussion about the existence or not of the basic requirements for the configuration of the employment relationship, protected by Brazilian legislation, which guarantees the worker covered by this legal relationship their labor rights. For that, through jurisprudential and bibliographical research, it analyzes the process of uberization of the modern worker, especially in times of pandemic of Covid-19, to identify aspects/information that help to understand if uberization is configured as a job. Finally, it is concluded that with the advent of the Covid-19 pandemic, the number of informal workers who became uberized increased; the Brazilian judiciary has not yet established a peaceful position regarding the recognition of employment relationship; it is necessary to have its own legislative regulation, aiming to legalize the situation of these workers.
\end{abstract}

Keywords: Covid-19; Crowdsourcing; Working relationships.

\section{Resumen}

Con la pandemia de Covid-19, el desempleo aumentó exponencialmente, presentando el crowdsourcing, es decir, el trabajo uberizado, como una salida para muchos trabajadores desempleados. Este artículo tiene como objetivo analizar con mayor profundidad el proceso de uberización de las personas, proponiendo una discusión sobre la existencia o no de los requisitos básicos para la configuración de la relación laboral, amparada por la legislación brasileña, que garantiza al trabajador amparado por esta relación jurídica, sus derechos laborales. Para eso, a través de la investigación jurisprudencial y bibliográfica, analiza el proceso de uberización del trabajador moderno, especialmente en tiempos de pandemia de Covid-19, identificar aspectos / información que ayuden a comprender si la uberización se configura como un trabajo. Finalmente, se concluye que con el advenimiento de la pandemia Covid-19, aumentó el número de trabajadores informales que se uberizaron; el poder judicial brasileño aún no ha establecido una posición pacífica con respecto al reconocimiento de la relación laboral; es necesario contar con un reglamento legislativo propio, con el objetivo de legalizar la situación de estos trabajadores.

Palabras clave: Covid-19; Crowdsourcing; Relaciones de trabajo. 


\section{Introdução}

A pandemia causada pelo Coronavírus - COVID-19 (sigla em inglês para Coronavirus Disease 2019) trouxe mudanças expressivas através da implementação de uma política de distanciamento social, indispensável para o combate ao vírus que afetou todas as esferas sociais, embora as interações interpessoais sejam necessárias. Destaca-se dentre essas esferas, a economia e por sua consequência direta, as relações de trabalho decorrente desta.

No Brasil, com o objetivo de minimizar os danos da esfera econômica, foram editadas pelo Governo Federal, diversos atos normativos trabalhistas, sendo os mais relevantes as Medidas Provisórias 927/2020 e 936/2020, que surgiram com o objetivo de flexibilizar os ajustes entre empregados e empregadores.

Nesse viés, apesar de terem ocorrido algumas alterações na legislação trabalhista, que visavam diminuir os impactos nos índices de desemprego através da flexibilização do contrato de trabalho, tornou-se perceptível que as relações laborais sofreram expressivas mudanças que devem ser analisadas mais profundamente, podendo-se destacar a diminuição das relações formais de trabalho e o aumento expressivo das relações informais, que elevaram expressamente a figura do "crowdsourcing", também conhecido como "uberização".

Nesse contexto, temos uma realidade que está sendo transformada de forma contínua e extremamente rápida, o que leva o Sistema Jurídico Brasileiro a não conseguir se adequar a esse dinamismo, de modo que existem diversas situações nas quais a legislação não consegue tutelar de forma apropriada. Por isso, o "crowdsourcing" pode, potencialmente, ser visualizado como uma das formas de trabalho precarizado, já que se utiliza da omissão legislativa para ludibriar os eventuais vínculos empregatícios necessários à garantia dos direitos.

Este artigo objetiva analisar de forma mais profunda o processo de uberização, propondo uma discussão acerca da existência ou não dos requisitos básicos para a configuração do vínculo de emprego, tutelado pela legislação trabalhista brasileira.

De cunho qualitativo, este estudo fundamenta-se teoricamente, dentre outros, em Marx (2010; 2013) e Saviani (2007) para discutir a relação do homem com a natureza a partir do trabalho da comunidade primitiva à sociedade capitalista; Nascimento (2018), Delgado (2019), Antunes (2020) e Carelli (2018) ao analisar o processo de uberização do trabalhador moderno, sobretudo em tempos de pandemia da Covida-19. Ademais, faz uso de pesquisa Jurisprudencial, objetivando identificar aspectos/informações, aspectos/informações que ajudem a compreender se a uberização configura-se como emprego.

\section{O Trabalho na Sociedade Capitalista}

A intervenção do homem na natureza causa uma dupla transformação: a natureza é transformada pelo homem tendo em vista as suas necessidades imediatas, ao passo que este homem transforma a si mesmo em uma relação objetiva com a natureza. Podemos afirmar, portanto, que o trabalho funda o homem, pois como pondera Marx (2013, p. 255) o “[...] trabalho é, antes de tudo, um processo entre o homem e a natureza, processo este em que o homem, por sua própria ação, media, regula e controla seu metabolismo com a natureza”. Esse processo de trabalho produz valores de uso, isto é, através da atividade realizada, o homem apropria-se dos elementos naturais para a satisfação de necessidades humanas.

No desenvolvimento das sociedades primitivas a relação entre seus membros era mediada pelo trabalho coletivo, de modo que tudo que produziam servia para a manutenção de todos os membros da comunidade. A educação era espontânea, pois não existia uma instituição formal responsável pelo ensino, e integral porque os membros recebiam e elaboravam os ensinamentos. Desse modo, as experiências eram validadas e transmitidas entre as gerações objetivando a manutenção da espécie. 
Com o surgimento da divisão da sociedade em classes e da propriedade privada, resultantes das modificações introduzidas nas técnicas do trabalho, pela produção de excedente e o intercâmbio dos produtos, instituiu-se, na sociedade antiga a educação formal, destinada à classe dos proprietários (de terras) e a educação geral para os não-proprietários (escravos), reflexo da separação entre trabalho material e trabalho intelectual.

Na sociedade feudal, cuja base econômica centrava-se na agricultura, a dualidade escolar se perpetuou: a educação da classe dominante agora mantinha-se sob forte influência da Igreja Católica, enquanto a classe pobre era educada pelo trabalho ao produzir a sua existência e a dos seus senhores. Saviani (2007, p. 158) destaca que "[...] o avanço das forças produtivas, ainda sob as relações feudais, intensificou o desenvolvimento da economia medieval, provocando a geração sistemática de excedentes e ativando o comércio", dando origem à sociedade capitalista que passou a ser estruturada não pelo direito natural, como nas sociedades anteriores, mas segundo o direito positivo, tornando-se uma sociedade contratual, que assegura o direito à propriedade privada, acentuando ainda mais a divisão social do trabalho em diferentes classes. Nesse período, a agricultura passa a ser subordinada à indústria, base para o desenvolvimento das cidades.

A Revolução Industrial modificou a sociabilidade do trabalho ao introduzir a maquinaria nas fábricas, trazendo efeitos imediatos aos trabalhadores que passaram ao trabalho mecanizado. Conforme afirma Marx (2013, p. 445): “[...] ela deve baratear mercadorias e encurtar a parte da jornada de trabalho que o trabalhador necessita para si mesmo, a fim de prolongar a outra parte de sua jornada, que ele dá gratuitamente para o capitalista. Ela é meio para a produção de mais-valor”. Nessa esteira, surge uma contradição imanente à introdução da maquinaria na fábrica, pois ao mesmo tempo que as máquinas são utilizadas pelo capitalista para extração do mais-valor, aumentando a força produtiva de trabalho, isto é, produzindo mais mercadorias em menos tempo, reduz o número de trabalhadores, criando uma população operária excedente.

Como o lucro advém da exploração de capital variável, um dos efeitos que recaiu sobre o trabalhador foi que a força exclusivamente masculina deixou de ser necessária na fábrica, sendo admitido também o trabalho feminino e o trabalho infantil. Logo, "[...] esse poderoso meio de substituição do trabalho e de trabalhadores transformou-se prontamente num meio de aumentar o número de assalariados, submetendo ao comando imediato do capital todos os membros da família dos trabalhadores, sem distinção de sexo nem idade" (Marx, 2013, p. 468).

Outro efeito imediato sobre o trabalhador foi o prolongamento da jornada de trabalho, visto que quanto mais a máquina é utilizada nos seus primeiros anos de vida, mais ela produz, embora encurte o seu tempo. No entanto, o capitalista sabe que se deixar a máquina parada o investimento realizado em capital constante pode ser perdido, pois máquinas mais modernas são introduzidas no mercado sistematicamente. Ávido pelo lucro, o capitalista encontra como meio de extrair maisvalia, a ampliação da jornada de trabalho dos operários, que se dá através da redução de trabalhadores, da transformação do capital variável investido nos salários dos trabalhadores substituídos pela maquinaria e, por conseguinte, da extração do maistrabalho. Desse modo, "[...] a máquina joga por terra todas as barreiras morais e naturais da jornada de trabalho" (Marx, 2013, p. 480) e, com isso, o capitalista amplia o grau de exploração da força de trabalho, encurtando o trabalho necessário e aumentando o mais-trabalho.

A intensificação do trabalho é mais um efeito imediato que incide sobre o trabalhador. A jornada de trabalho prolongada gerou revolta na classe trabalhadora obrigando o Estado a delimitar, junto às fábricas uma jornada normal de trabalho. No entanto, para manter a extração de lucro, os capitalistas utilizaram-se da maquinaria para explorar a produção de mais-valor relativo, embora a jornada de trabalho tenha sido reduzida. Nesse sentido, Marx (2013, p. 483), ressalta que "[...] dentro de certos limites, o que se perde em duração ganha-se no grau de esforço realizado. Mas o capital assegura, mediante o método de pagamento, que o trabalhador efetivamente movimente mais força de trabalho". A maquinaria, portanto, é utilizada pelos capitalistas para extração de mais-trabalho, uma vez que o lucro não advém da própria maquinaria, mas da exploração do trabalho humano. 
Nessa esteira, a divisão de classes sociais e a propriedade privada engendram um metabolismo social marcado pela exploração dos donos dos meios de produção, transformando o trabalhador em uma "[...] mercadoria tão mais barata quanto mais mercadorias cria" (Marx, 2010, p. 80). Como consequência das relações capitalistas de produção, o homem torna-se parcial e alienado, pois passa a realizar apenas parte do processo de produção e, ao final, não se reconhece na mercadoria que produz, isso porque, por um lado, o trabalhador não é o dono dos meios de produção e por outro, sua subsistência depende do salário que recebe com a venda da sua força de trabalho que dá apenas para sobreviver. Marx (2010, p. 82) conclui que

O trabalho produz maravilhas para os ricos, mas produz privação para o trabalhador. Produz palácios, mas cavernas para o trabalhador. Produz beleza, mas deformação para o trabalhador. Substitui o trabalho por máquinas, mas lança uma parte dos trabalhadores de volta a um trabalho bárbaro e faz da outra parte máquinas. Produz espírito, mas produz imbecilidade, cretinismo para o trabalhador.

Para tanto, o modo de produção capitalista ao invés de humanizar o trabalhador, contribui para a sua desumanização, transformando-o em um ser que não se sente livre no trabalho, mas sim fora dele ao realizar suas funções animais: comer, beber e procriar (Marx, 2010). A relação ontológica entre ser humano e natureza através do trabalho é rompido, visto que este é um meio utilizado pelos capitalistas para explorar, alienar e tornar o trabalhador em um ser parcial e desumanizado.

As modificações no processo produtivo, provocam a exigência de uma reorganização em toda uma sistemática capitalista, e tecnologias cada vez mais modernas são empregadas dentro desse processo de produção. Em decorrência desses fatores, temos um gigantesco aumento da produtividade, e uma diminuição expressiva da necessidade da força de trabalho para atingir a produção de mercadorias (Fontes, 2017).

A hiperprodução do capital, juntamente à redução expressiva de trabalhadores com vínculos de empregos formais, proporciona dentro desse contexto, o desemprego e a precarização, tornando a competitividade dentro do setor de aplicativos ainda mais preocupante, pois a concorrência exacerbada é capaz de ocasionar uma ainda maior redução das tarifas. Dessa forma, o capital passa a exigir cada vez mais da força de trabalho, gerando controle e dependência. (Carelli, 2018).

Na seção a seguir, ampliaremos nossas discussões a respeito da precarização do trabalho, a partir da informalidade que se avultou com o desemprego.

\section{Informalidade e Precarização}

É no contexto da sociedade capitalista moderna agravado pela pandemia da Covid-19 que surge mais uma forma de precarização da relação de emprego, o crowdsourcing ${ }^{l}$,

Para o sistema normativo brasileiro, uma relação jurídica é caracterizada pelo vínculo entres sujeitos de direito, proporcionando o surgimento, a reforma e a extinção de determinadas prerrogativas. A partir de uma ótica latu sensu, o trabalho, pode ser admitido como toda e qualquer atividade, independente do agente, da natureza, ou de sua destinação. Nas lições de Amauri Mascaro Nascimento (2018 p. 25), a relação jurídica que envolve o trabalho, deve ser compreendida como o “[...] universo de relações jurídicas ou contratos de atividade nos quais o objeto preponderante do vínculo jurídico é a atividade mesmo da pessoa que presta serviços para outra, para uma empresa ou para uma pessoa física, portanto, gênero, como, também, o que não nos parece acontecer, relação de trabalho como sinônimo de relação de emprego".

Nesse sentido, sob essa perspectiva compreende-se que o termo "contrato de trabalho", configura um gênero, que se subdivide em diversas espécies. Por sua vez, ao tratar-se o contrato de emprego, subespécie do contrato de trabalho, observa-se

\footnotetext{
${ }^{1}$ Definição Merrian-Webster (s/p): “[...] a prática de obter os serviços, ideias ou conteúdo necessários, solicitando contribuições de um grande grupo de pessoas e especialmente da comunidade online, em vez de funcionários ou fornecedores tradicionais".
} 
um ajuste que tem como delimitador básico a lei, que exige para sua configuração de alguns requisitos. Conforme ensina Mauricio Godinho Delgado (2019, p. 289):

Resulta da síntese de um diversificado conjunto de fatores (ou elementos) reunidos em um dado contexto social ou interpessoal. Desse modo, o fenômeno sociojurídico da relação de emprego deriva da conjugação de certos elementos inarredáveis (elementos fático-jurídicos), sem os quais não se configura a mencionada relação. Os elementos fáticojurídicos componentes da relação de emprego são cinco: (a) a prestação de trabalho por pessoa física a um tomador qualquer; (b) a prestação efetuada com pessoalidade pelo trabalhador; (c) também efetuada com não eventualidade; (d) efetuada ainda sob subordinação ao tomador dos serviços; (e) prestação de trabalho efetuada com onerosidade.

O primeiro requisito apontado, trata-se da exigência de que o trabalhador em questão seja uma pessoa natural, portanto, conforme as diretrizes impositivas do Direito Trabalhista Brasileiro, o empregado não pode ser pessoa jurídica. Outro requisito que deve existir de forma cumulativa ao anterior é o da pessoalidade, que visa externar o vínculo entre o empregador e aquele empregado, que deve ser específico, não podendo este ser substituído a qualquer tempo, sem prejudicar a relação jurídica existente, nem se estendendo a terceiros, sejam herdeiros legítimos ou necessários.

No mesmo sentido, a não eventualidade surge como requisito que demonstra que o trabalhador deve exercer a sua função habitualmente, ou seja, sem o requisito da continuidade da relação, o trabalhador não poderá apresentar o vínculo empregatício.

Por fim, o último requisito é o da subordinação, que determina a necessidade do empregado de seguir os comandos emanados do empregador, devendo se submeter ao poder de direção deste, sendo este, um dos elementos caracterizados mais importantes dentro de uma relação de emprego. Conforme aduz Delgado (2019, p. 99): "Subordinação é conceito que traduz a situação jurídica derivada do contrato de trabalho mediante a qual o empregado se obriga a acolher a direção do empregador sobre o modo de realização da prestação de serviços".

Vale salientar, que o conceito de subordinação não pode ser confundido com uma subordinação necessariamente direta, ou seja, essa subordinação é entendida como a incorporação do exercício do tomador dos serviços, independentemente do acolhimento de ordens expressas, mas acolhendo, fundamentalmente sua dinâmica de sistematização e funcionamento (Delgado, 2019).

\section{Tecnologias Digitais e Novas Relações de Trabalho}

Nas sociedades anteriores à modernidade, as profissões tinham como princípio basilar o da hereditariedade, através do qual determinado ofício era passado de pai para filho como tradição, contudo, com a modernização das relações de trabalho, tivemos diversas mudanças. Os impactos sociais nas relações de emprego no decorrer dos anos, causados pela automação e transformações do mercado, foram suficientes para estremecer a tênue linha responsável por delimitar o trabalho de qualquer um. Conforme explica Rosa (2011), tivemos uma transição forçada no que se trata da escolha da profissão, pois o que anteriormente era feita uma vez na vida, passou a ocorrer algumas vezes dentro do ciclo de trabalho de um indivíduo, surgindo, portanto, um aumento expressivo das relações de trabalho informais, bem como dos trabalhos de alta rotatividade.

O trabalho precarizado surge dentro de um contexto de mudanças estruturais do capitalismo, no qual as empresas, buscando otimizar seus lucros através da máxima flexibilização das relações de trabalho, realizam uma "superexploração" da classe trabalhadora, criando a chamada "escravidão digital" (Antunes, 2018).

Essa precarização, segundo Bourdieu (1998, p. 124-125), advém de uma vontade política, e não necessariamente de uma "fatalidade econômica", pois esta é "[...] uma situação generalizada e permanente de insegurança, visando obrigar os trabalhadores à submissão, à aceitação da exploração". 
Logo, em decorrência de não possuir os vínculos formais com a concomitante presença de pessoalidade, subordinação, onerosidade, habitualidade, além da exigência desse trabalho ser realizado por pessoa física, esse trabalhador informal não possuirá uma proteção efetiva das normas trabalhistas existentes.

Conforme os dados apresentados pelo Instituto Brasileiro de Geografia e Estatística (Agência Brasil, 2021), no último trimestre, finalizado em maio de 2021, houve um aumento de $40 \%$ nas taxas relativas à informalidade no mercado de trabalho, totalizando 34,7 milhões de trabalhadores entre um contingente de 86,7 milhões, ou seja, dentre os trabalhadores ativos no mercado de trabalho, uma parcela superior a $40 \%$ exerce suas funções de maneira informal, sem uma proteção apropriada dos direitos trabalhistas, a exemplo de benefícios previdenciários, seguro desemprego, $13^{\circ}$ salário e férias remuneradas.

Parte do aumento dessa crescente informalidade se deu com a queda expressiva das ofertas de empregos formais, associada à popularização de aplicativos de Economia Compartilhada de Serviços denominados de crowdsourcing, popularmente conhecido como uberização, em referência à empresa que efetivamente tornou esse modelo de negócio um sucesso consagrado. Apesar do termo "uberização" ter se popularizado, temos diversas outras espécies de serviços que utilizam essa mesma metodologia, a exemplo do Airbnb (imóveis); Blabla Car (Compartilhamento de Viagens); Uber Eats (Entrega de Alimentos); Ifood (Entrega de Alimentos); Rappi (Entrega de Variados Bens); Lending Club (Empréstimos), dentre diversos outros que vão se popularizando e se consolidando no mercado.

Diante da conjuntura social já tratada, esse novo método advindo de plataformas digitais, ocasionou diversos problemas relativos à precarização das condições do trabalhador, conforme explicita Ricardo Antunes (2020, p. 14): "Uberização do trabalho, distintos modos de ser da informalidade, precarização ilimitada, desemprego estrutural exacerbado, trabalhos intermitentes em proliferação, acidentes, assédios, mortes e suicídios: eis o mundo do trabalho que se expande e se desenvolve na era informacional, das plataformas digitais e dos aplicativos".

Em decorrência de todo esse contexto, é perceptível que estamos diante de uma obscura área no que tange a regulamentação desses trabalhadores de plataformas digitais, uma vez que não fazem parte, de forma objetiva, de uma categoria específica, a partir da ótica do Direito do Trabalho.

As atividades desempenhadas por estes trabalhadores de aplicativo, além de não possuírem uma proteção específica do direito do trabalho, possuem peculiaridades que dificultam a realidade vivida, especialmente em períodos de pandemia.

Consoante Ludmila Costhek (apud Machado, 2017, s/p), temos que:

Ao mesmo tempo em que se livra do vínculo empregatício, a uberização mantém, de formas um tanto evidentes, o controle, gerenciamento e fiscalização sobre o trabalho, adverte. Para ela, a perspectiva é ainda inteiramente aliada com a ideia de empreendedorismo de si. Trata-se então da consolidação da transformação do trabalhador em um nanoempreendedor de si próprio.

O termo "nanoempreendedor" apresentado pela autora, faz jus à realidade vivida por esses trabalhadores de aplicativos, pois exercem suas funções com o ônus de empreendedor, sem o mínimo suporte em suas atividades.

Os equipamentos e as despesas para o exercício de suas funções, bem como os integrais riscos da atividade, são todos imputados ao trabalhador, sendo necessário, realizar longas jornadas de trabalho para conseguir o seu sustento, se assemelhando muito com o período da Revolução Industrial (Basso, 2018), pois apesar de termos novos contornos dando origem a essas relações, as jornadas de trabalho necessárias para receber uma remuneração minimamente digna, ultrapassam as 10 horas diárias, em decorrência da baixa comissão paga, juntamente à alta necessidade desses trabalhadores em decorrência do desemprego (De Stefano, 2017).

Vale salientar, que esses trabalhadores são controlados, por meio de premiações em momentos com poucas ofertas, ou para realizar trabalhos em áreas de risco. Por outro lado, caso não realizem as atividades designadas são punidos de diversas 
formas que vão, desde a diminuição dos valores a serem recebidos, ao desligamento do sistema (Carelli, 2018).

Os tribunais nacionais ao tratarem do tema têm se posicionado no sentido de responder a dois questionamentos básicos: seriam esses trabalhadores de aplicativos autônomos? Ou essas empresas utilizam o crowndsourcing como uma forma de dissimular a caracterização de emprego para a diminuição dos encargos trabalhistas? Discutiremos, portanto, essas questões na próxima seção.

\section{Posicionamento dos Tribunais em Âmbito Nacional: caso Uber}

O aplicativo Uber, administrado pela empresa multinacional norte-americana - Uber Technologies Inc. -, e responsável por prestar serviços na área do transporte privado urbano, através da busca por motoristas baseada na localização, foi, sem dúvidas, a primeira grande empresa a se utilizar desse método de Economia Compartilhada para proporcionar serviços e também a primeira a gerar discussões severas no âmbito trabalhista.

A primeira corrente, mais formalista, posiciona-se pela inexistência de qualquer vínculo que propicie a classificação desses motoristas como empregados, sob a justificativa de que a Uber tem, como objetivo central, o fornecimento de negócios relacionados à tecnologia e não ao transporte de passageiro. Nessa mesma ótica, a empresa seria somente um intermediário, como uma ferramenta de trabalho, não apresentando, portanto, um vínculo empregatício.

Nesse mesmo sentido, após o Tribunal Regional do Trabalho da $2^{a}$ Região de São Paulo, proferir sentença acolhendo o parecer realizado pelo Ministério Público do Trabalho, no qual advogava pelo reconhecimento do vínculo empregatício da relação, os ministros da $5^{\text {a }}$ Turma do Tribunal Superior do Trabalho ${ }^{2}$ reformaram a decisão. Segundo o relator do recurso, o ministro Breno Medeiros, compreendeu-se que em decorrência das provas apresentados, o motorista de aplicativo tinha plena autonomia para estabelecer os horários em que gostaria de trabalhar e que, portanto, não teria o vínculo empregatício.

No entanto, apesar do exposto por esta corrente, compreende-se que a realidade proposta pela Uber, bem como dos demais aplicativos, é bastante diferente. Dessa forma, devemos acrescer à análise dessa discussão, a realidade fática, e não somente um formalismo, da maneira que ela se apresenta.

Ou seja, ainda que o trabalhador/empregador não tenha seguido todas as formalidades exigidas pela legislação, devese observar a realidade prática, ainda assim protegendo o trabalhador. Em virtude disso, por meio de diversas ações trabalhistas, a categoria de motoristas procurou o reconhecimento do vínculo de emprego com a empresa - Uber Brasil -, e por consequência buscou a garantia dos direitos que advém com a configuração dessa relação. A demanda relativa ao enquadramento desse vínculo, há muito deixou de ser uma mera discussão doutrinária, tomando espaço na Justiça do Trabalho. Essas reclamações trabalhistas, fundamentam-se basicamente no reconhecimento dos elementos responsáveis por configurar o vínculo de emprego, tomando por base a realidade fática enfrentada por estes trabalhadores. Pois, segundo a interpretação dos reclamantes, os elementos: Pessoalidade, Não-Eventualidade, Onerosidade, trabalho realizado por Pessoa Física e em especial a Subordinação Jurídica estão presentes.

Nesse mesmo sentido, tivemos o entendimento da $8^{\mathrm{a}}$ Turma do Tribunal Regional do Trabalho, $4^{\mathrm{a}}$ Região ${ }^{3}$, através do relator, Desembargador Marcelo Ferlin D'ambroso, que reconheceu a existência do vínculo empregatício entre a Uber Brasil e o motorista (autor da ação).

Independentemente da espécie de relação de trabalho em questão, é possível determinar que estariam presentes a pessoalidade e a onerosidade, seja a relação empregatícia ou autônoma, gerando os aspectos vinculados à subordinação e à não eventualidade incertezas dentro desse contexto.

2 TST - RR: 10001238920175020038, Relator: Breno Medeiros, Data de Julgamento: 05/02/2020, $5^{\mathrm{a}}$ Turma, Data de Publicação: DEJT $07 / 02 / 2020$.

${ }^{3}$ TRT-4 - RORSUM: 00207503820205040405, Data de Julgamento: 23/09/2021, $8^{\text {a }}$ Turma. 
Para sanar essas dúvidas, aduz o relator, naquilo que tange a subordinação:

Estabelecida tal premissa, salienta-se, ainda, que, ao revés do aludido na sentença recorrida, está plenamente presente a subordinação: quer sob o aspecto subjetivo e especialmente sob o aspecto objetivo, uma vez que notoriamente as atividades desenvolvidas pela pessoa trabalhadora se prestam a realizar o objetivo social da empresa, como, aliás, reconhecido na decisão, quando explicitamente refere que a demandada atua na atividade de transportes. $\mathrm{O}$ fato da pessoa trabalhadora se utilizar de recursos próprios para prestar serviços (veículo, manutenção e combustível), por si só não atesta qualquer independência na relação, uma vez que tais condições são literalmente impostas: inexiste margem de escolha de quem presta serviços para a Uber, no particular, ao contrário, se adere a uma modalidade de subordinação por evidente necessidade, em franca ofensa ao disposto no art. $9^{\circ}$ da CLT (relação de emprego escamoteada).

A subordinação sob o âmbito subjetivo igualmente se encontra presente, ainda que com a roupagem diferenciada das relações de emprego, todavia, ao fim e ao cabo está muito claro que é a ré que define quem lhe presta serviços, o período de tempo, como também os motivos pelos quais os motoristas podem ser excluídos pela plataforma (ainda que "terceirize" a avaliação dos motoristas aos usuários do aplicativo), além de ser responsável pela remuneração do trabalho. Como já se disse, a demandada é a maior empresa de prestação de serviços de transporte de passageiros sem nem mesmo possuir frota - negócio altamente lucrativo no qual pulverizam-se os prejuízos e responsabilidades enquanto concentra-se monopolicamente o lucro e as vantagens. (Brasil, 2021, s/p, grifos nossos).

Já na configuração da não-eventualidade, temos que via de regra, a pretensão da grande maioria dos motoristas de aplicativo é de exercer essa função habitualmente ${ }^{4}$. Ainda que não possa exercer a função de motoristas todos os dias, o dia todo, nada impede a configuração da habitualidade.

No julgado apresentado pelo Tribunal Superior do Trabalho, o argumento levantado pelos ministros, ao negarem a existência do vínculo empregatício, versava predominantemente sobre a possível existência de uma autonomia de horários para o trabalhador. No entanto, na realidade fática, temos um rigoroso controle por parte dos aplicativos, uma vez que quando o trabalhador produz menos, aos poucos, suas solicitações de viagens passam a ser reduzidas, ou seja, estamos diante, portanto, de um autogerenciamento subordinado (Abílio, 2019).

Diante disso, é necessário analisarmos, utilizando-se do princípio da primazia da realidade sobre a forma ${ }^{5}$, para que assim, possamos cada vez mais, proteger o trabalhador dessas situações de precarização, identificando essas obscuridades da legislação trabalhista e reconhecendo esses vínculos fáticos de forma rápida, com o intuito de evitar danos a toda uma categoria.

\section{Considerações Finais}

O trabalho é um elemento essencial na formação do indivíduo em sociedade (Jucá; Almeida; Silva, 2021), no entanto, o surgimento da sociedade capitalista engendra um modelo de divisão do trabalho marcado pela exploração dos donos dos meios de produção sobre os desprovidos desses meios. O Estado, através do direito positivo, legaliza o processo de expropriação da força de trabalho humana com vistas ao lucro exacerbado. Antes compreendido como coletivo, o trabalho agora passa a servir apenas para que os capitalistas continuem enriquecendo às custas dos trabalhadores.

Na sociedade do capital, a Economia Compartilhada, apresenta-se como uma forma de encobrir a precarização, sob diversas justificativas de flexibilização. Esses aplicativos que surgem no mercado com diversas promessas de autonomia no trabalho, utilizam frequentemente ideias como: "seja seu próprio patrão" ou "defina sua carga de trabalho" para encobrir a

\footnotetext{
4 "Não-eventualidade é o mesmo que habitualidade, não se confundindo com 'continuidade'. O trabalho executado em apenas dois dias da semana, p.ex., mas habitualmente prestado, não é eventual, mas usual, apesar de não ser diário (não ser contínuo, ininterrupto)” (Espaço Jurídico, 2012, s/p).

5 "O conteúdo do contrato não se circunscreve ao transposto no correspondente instrumento escrito, incorporando amplamente todos os matizes lançados pelo cotidiano da prestação de serviços" (Delgado, 2019, p. 244).
} 
exploração da força de trabalho humana. No entanto, temos um sério problema quando existem milhares de brasileiros com seus direitos suprimidos, e essa situação se torna um verdadeiro problema social da nação.

Com o advento da pandemia ocasionada pelo Coronavírus, os problemas dos trabalhadores informais, que já não eram poucos, cresceram exponencialmente, pois estes não possuíam nenhuma proteção que lhes garantisse a mínima segurança, estando reféns do exercício da função, visto que se esse trabalhador de aplicativos não trabalhar, será difícil sustentar sua família.

Diante disso, a confirmação do vínculo empregatício é essencial para garantir direitos como seguro desemprego, $13^{\circ}$ salário e férias remuneradas, sendo o ingresso na Justiça do trabalho, a forma mais rápida de tentar modificar essa realidade. Apesar do exposto, a jurisprudência brasileira se mostrou bastante instável, pendendo levemente à não consideração do vínculo de emprego. Vale salientar, que apesar de tudo, temos um contexto promissor, com diversas decisões que vêm reconhecendo esse vínculo e efetivando a aplicação do princípio da primazia da realidade.

Em suma, é necessária uma regulamentação legislativa própria, com vistas a abarcar essas situações de forma específica e, por consequência, atualizar os novos parâmetros responsáveis por configurar uma relação de emprego, de tal forma a garantir a efetividade do direito do trabalho e proteger o trabalhador por completo.

Salientamos, por fim, que este estudo pode ser ampliado, visando contribuir com as discussões acerca da precarização do trabalhador informal, sobretudo no decorrer do período pós-pandêmico, mediante uma análise criteriosa sobre a situação desses trabalhadores.

\section{Referências}

Abílio, L. C. (2019). Uberização: do empreendedorismo para o autogerenciamento subordinado. Revista Psicoperspectivas, 18 (3). http://dx.doi.org/10.5027/psicoperspectivas-vol18-issue3-fulltext-1674. 1-11.

Agência Brasil. (2021). Taxa de informalidade no mercado de trabalho sobe para 40\%, diz IBGE. https://agenciabrasil.ebc.com.br/economia/noticia/2021 07/taxa-de-informalidade-no-mercado-de-trabalho-sobe-para-40-diz-ibge.

Antunes, R. (2020). Coronavírus: o trabalho sob fogo cruzado. Boitempo. E-book.

Antunes, R. (2018). O privilégio da servidão: o novo proletariado de serviços na era digital. Boitempo.

Basso, P. (2018). Tempos Modernos, Jornadas Antigas. Campinas: Editora Unicamp.

Bourdieu, P. (1998). A precariedade está hoje por toda parte. In: Bourdieu, P. Contrafogos, Ed. Jorge Zahar. 119-127.

Brasil. (2021). Tribunal Regional do Trabalho (Região, 4.). Acordão 0020750-38.2020.5.04.0405. Tribunal Regional do Trabalho da 4a Região. https://www.trt4.jus.br/pesquisas/rest/cache/acordao/pje/JeQ1HT5XS2_vvUhDk62uGg?.

Brasil. (2020). Tribunal Superior do Trabalho (5 ${ }^{\mathrm{a}}$ Turma). Acordão TST-RR-1000123-89.2017.5.02.0038. Brasília: Tribunal Superior do Trabalho. http://aplicacao4.tst.jus.br/consultaProcessual/consultaTstNumUnica.do;jsessionid=3E7568E1B0E0A83FC311062C676DDF06.vm152?conscsjt=\&numeroTst $=1000123 \&$ digitoTst $=89 \&$ anoTst=2017\&orgaoTst $=5 \&$ tribunalTst $=02 \&$ varaTst $=0038 \&$ consulta=Consultar.

Carelli, R. L. (2018). Trabalho no século XXI: as normas formas de trabalho por plataformas. https://www.jota.info/opiniao-e-analise/artigos/trabalho-noseculo-xxi-as-novas-formas-de-trabalho-por-plataformas-30072018.

Carelli, R. L. (2016). O Uber, o táxi e a exploração dos motoristas. http://www.gazetadigital.com.br/editorias/opiniao/o-uber-o-taxi-e-a-exploracao-dosmotoristas/480952.

De Stefano, V. (2017) Labour is not a technology - reasserting the declaration of philadelphia in times of platform-work and gig-economy. IUS Labor. http://relats.org/documentos/OIT.DIGIT.Distefano2.feb.pdf.

Delgado, M. G. (2019). Curso de direito do trabalho. (5a ed.).

Espaço Jurídico. (2012). Elementos identificadores da relação de emprego (requisitos da relação de emprego). Espaço Jurídico. https://www.espacojuridico.com/blog/elementos-identificadores-da-relacao-de-emprego-requisitos-da-relacao-de-emprego/.

Fontes, V. (2017). Capitalismo em tempos de uberização: do emprego ao trabalho. Marx $e \quad o$ Marxismo, 5(8). 45-67. https://www.niepmarx.blog.br/revistadoniep/index.php/MM/article/view/220.

Jucá, E. G., Almeida, E. R., \& Silva, R. J. N. da. (2021). As relações entre o trabalho e a linguagem. Research, Society and Development, 10(12), e388101219512. https://doi.org/10.33448/rsd-v10i12.19512 
Research, Society and Development, v. 10, n. 16, e360101624051, 2021

(CC BY 4.0) | ISSN 2525-3409 | DOI: http://dx.doi.org/10.33448/rsd-v10i16.24051

Machado, R. (2017). Uberização traz ao debate a relação entre precarização do trabalho e tecnologia. Revista do Instituto Humanista Unisinos. (503). http://www.ihuonline.unisinos.br/artigo/6826-uberizacao-traz-ao-debate-a-relacao-entre-precarizacao-do-trabalho-e-tecnologia.

Marx, K. (2010). Manuscritos econômicos-filosóficos. Boitempo.

Marx, K. (2013). O capital: crítica da economia política: Livro I: o processo de produção do capital. Tradução: Rubens Enderle. Boitempo.

Merriam-Webster. (s.p.). Crowdsourcing. No dicionário Online Merriam-Webster. https://www.merriam-webster.com/dictionary/crowdsourcing.

Nascimento, A. M. (2018). A competência da Justiça do Trabalho para a relação de emprego. In: COUTINHO, Grijalbo Fernandes; FAVA, Marcos Neves (Coord.). Nova competência da Justiça do Trabalho.

Rosa, H. (2011). Aceleración social: consecuencias éticas y políticas de una sociedad de alta velocidad desincronizada. Persona Y Sociedad, 25(1). https://personaysociedad.uahurtado.cl/index.php/ps/article/view/204. p. 9-49.

Saviani, D. (2007). Trabalho e educação: fundamentos ontológicos e históricos. Revista Brasileira de Educação, 12(34). 152-180. 